\section{Life Span of Doctors}

SIR,-I believe it is a recognized fact that longevity is not the lot of the medical profession. The B.M.F. obituary list saddens me when I see so many men dying in the 50 and 60 age groups, just when their wisdom and experience are so valuable and can ill be spared. Is this a worse record than other professions?

On 27 March (p. 866) the average age was 62 except for one of 90 , but that was a woman.

Is this mostly due to overwork and worry? It seems a very bad advertisement for Medicine when doctors themselves succumb at an unnecessarily early age.-I am, etc.,

Cheltenham

Dorothy E. MASON.

\section{Hypertension and Toxaemia}

SIR,-I find it difficult not to reply to the query in the last line of your leading article (20 March, p. 738), "Are words and their meanings obscuring the truth ?" In my opinion they are.

"Toxaemia" appeared in Eden's Manual of Midwifery, 1st. ed., 1906, as a subtitle to "auto-intoxication" (by foetal waste products !). Sporadically since then the mythical toxin has been sought unsuccessfully, in the syncytium, in the red infarcts, and elsewhere.

Someone, Browne I think, invented the term pre-eclampsia to emphasize that albuminuria in pregnancy was not just a common occurrence in pregnancy; it was a sign that the patient was a potential eclamptic - so far, so good, but in doing so he made "pre-eclampsia" something peculiar to pregnant women, and took it out of the orbit of the general physician who might well have guided us to the correct path long ago

This thing called "toxaemia" or preeclampsia is in my view nothing more nor less than acute hypertension, and ought to be so named. Is this playing with words or is it important? I believe it to be of prime importance, for it then implies a renal origin, and renal biopsies have shown the specific lesion of "toxaemia." 1

It is the acute form of chronic hypertension ; it may, and often does, lead on to the chronic manifestation. Differences of opinion upon this point stem from a curious and regrettable refusal to agree on a figure above which a patient shall be said to be hypertensive, and to the fact that in your words " few of the contributions to the literature on toxaemia are comparable one with another." -I am, etc.,

London W.1.

$$
\text { C. K. Vartan. }
$$

REFERENCE 1 Pirani, C. L., Pollak, V. F., Lannigan, R., and

\section{Bacterial Endocarditis and Urology}

SIR,-Dr. J. D. Lloyd-Still's article concerning bacterial endocarditis due to Streptococcus faecalis and urinary tract infection (20 March, p. 768) is of importance. I enclose a report of a patient who developed bacterial endocarditis and meningitis due to Klebsiella aerogenes following urethral instrumentation.
A man of 79 who had bladder-neck obstrucion due to benign adenomatous enlargement of the prostate was admitted for prostatectomy. An intravenous pyelogram had revealed no abnormality. The blood urea was $55 \mathrm{mg}$./100 $\mathrm{ml}$. The serum acid phosphatase was 3 KingArmstrong units. Pre-operative culture of the urine yielded a moderate growth of Klebsiella aerogenes and a scanty growth of a proteus. When the urinary infection had been treated with tetracycline a transvesical prostatectomy was performed and a catheter left in situ for five days. Post-operative culture of urine yielded $\mathrm{Kl}$. aerogenes, which was treated first by a course of nitrofurantoin and later (after removal of the catheter) by a course of ampicillin. The patient continued to have dysuria and there was some incontinence, so three weeks after the prostatectomy cystoscopy was performed which showed some thickening of the prostatic bed. Therefore a urethral dilatation was carried out Following this instrumentation the patient's condition deteriorated and he became semi-comatose three days later. The urinary output diminished and the blood urea rose to $320 \mathrm{mg} . / 100 \mathrm{ml}$. A lumbar puncture three days after cystoscopy confirmed a clinical diagnosis of meningitis and culture of the cerebrospinal fluid yielded $\mathrm{Kl}$. aerogenes. $\mathrm{Kl}$. aerogenes was isolated also from a blood-culture taken at this time. The meningitis was treated with chloramphenicol, to which the organism was sensitive. Previous courses of antibiotics had been given in accordance with results of laboratory sensitivity tests. The patient failed to improve and died seven days after the onset of meningitis.

Necropsy findings showed purulent meningitis, aortic endocarditis, an inflamed bladder, prostatic shell, and posterior urethra associated with a perivesical abscess. There was also an extensive lobar pneumonia of the right lung and a septic splenic infarct.

$\mathrm{Kl}$. aerogenes is especially prone to cause infection of the urinary tract if there be some obstruction. As this organism often appears at other sites in the body, urethral instrumentation may prove to be a special hazard despite apparent adequate antibiotic cover.I am, etc.,

$$
\begin{aligned}
& \text { St. Albans City Hospital, } \\
& \text { St. Albans, Herts. }
\end{aligned}
$$

\section{Wanted, Minimum Standards}

SIR,-Whatever the terms of service and the rates of remuneration which are finally accepted by the profession, they must be comparable with, even competitive to, those conditions and income levels offered to British-qualified doctors in other countries. This, I feel, is absolutely essential, and must be the "yardstick" on which all our negotiations should be measured. We must also remember that, having gone so far towards resignation from the present form of general practice, we have accepted full responsibility for the future standards of general practice in this country.

General practice has survived in the N.H.S. because it was superimposed on the traditional form of general practice which had evolved over generations. But at what a cost !

Firstly, there is the irreplaceable loss to the profession of the thousands of Britishqualified doctors who, in order to practise medicine as it should be practised, have left this country. To these must be added the large number of doctors and medical students who will certainly leave the country unless we ensure adequate pay and conditions.

Secondly, the loss of financial and professional status which the general practitioner has been forced to accept has prevented him from providing himself with adequate working conditions and facilities, and this has made him a consultant- and hospitaldependent medical practitioner. This, above all else, has been responsible for the excessive work load on the hospital services.

Thirdly, the "brain-washing" caused by repeated hope and disappointment over the last 17 years which has made the general practitioner devalue himself in his own eyes. In 1939 an industrial practice in the poorer part of the Midlands with 2,100 patients, one-quarter panel patients at 10s. per year, and the remainder "club" patients at $6 \mathrm{~d}$. per week, brought in more than $£ 2,000$ per year, now worth $£ 10,000$ or more. Large though this income would be, most of it would be returned to the Inland Revenue unless the individual general practitioner used it to catch up on 17 years of poor conditions by improving his surgeries, increasing his ancillary help, and taking on more medical help as soon as it became available. And it would soon become available. Double the number of general practitioners in this country with British-qualified doctors; increase surgery facilities with modern diagnostic equipment ; take the excessive load off the hospital service by efficient domiciliary diagnosis and treatment; then, and only then, will the damage of 17 years of the N.H.S. be put to rights.

Unless we attain the minimum standards now we can look forward to general practice being run by "sub-assistant surgeons," qualified after three years at a politically upgraded technical college. And the fault will be ours.-I am, etc.,

Brownhills, Staffs.

D. M. FORSTER.

\section{Doctors, the Press, and Public Opinion}

Sir,-Our leaders have persuaded us to give the Minister a few more weeks in which to guarantee that the Pool system will be abolished and that the Review Body's calculations will no longer be Pool-based. We know that Dr. Cameron will not go back on his word or let the Minister make a fool of him, and we are confident that if, in June, all he has to show for his trouble is another clever Ministerial letter he will not shrink from recommending that the Guild send in our resignations on 30 June.

If $\mathrm{Mr}$. Robinson is wise enough to render this action unnecessary it will then remain to be seen whether the present members of the Review Body can approach their task unprejudiced by their declared belief that our remuneration has been adequate since 1948 . We must face the possibility that, having been committed to accepting the Review Body's pricing of a new contract, we may be given a price so low as to render the Charter meaningless. It will therefore be as well to keep our resignations in the pending tray until the new pay levels are announced. The Prime Minister is not obliged to accept the Review Body's advice, and neither are we.

Should the dispute boil up again, either in June or after pricing, we may expect renewed attacks in those newspapers constituting the anti-medical press. Doctors who are sensitive about what they believe to be their "image" should take heart from the observation that a "public opinion" which fluctuates so 